\title{
Skeletal and dental norms for Sudanese adults with Class I normal occlusion
}

\author{
Fadhil Y JASIM* \\ Adam I ADAM**
}

\section{ABSTRAC'T}

The purpose of this study is to establish skeletal and dental Norms for Sudanese adults by using lateral cephalometric radiography.

A lateral cephalometric analysis of normal Sudanese adults was accomplished on (27) males and (23) females aged (18) to (25) years with class I normal occlusion, with no previous orthodontic treatment and with harmonious faces.

Normative skeletodental cephalometric Standards for adult Sudanese males and females including (18) angular and (21) linear parameters were developed.

Skeletal comparison between males and females showed that:

- Males were significantly greater than females in lower facial height (LFH) and gonial (Ar.Go.Me) angles, while the females were significantly greater than males in mandibular bend (MB) and symphysis (B-Me-Mp) ones.

- Males were significantly longer than females in all the skeletal linear parameters except Wits appraisal and (A-N-Pog.) line, which shows no significant sex, difference.

- Males with longer cranial base longer upper andlower jaws.

- When comparing the dental angular parameters: Males demonstrated greater significant values than females in the interincisal (U1-L1) angle than the females, while the females were significantly greater than males in lower incisors inclination ( $\mathrm{L} 1-\mathrm{Mp})$ angle

- The Sudanese adults exhibited bimaxillary protrusion tendency.

Comparing the dental linear parameters: Males were significantly longer than the females in the upper posterior (UPDH), lower posterior (LPDH), and lower anterior (LADH) dental heights.

Key Words: Cephalometric norms, normal occlusion.

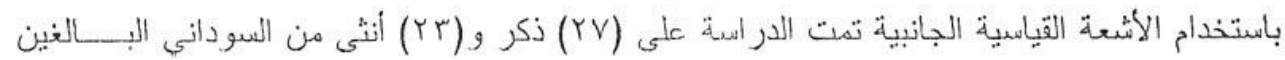

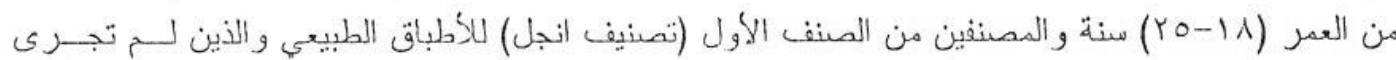

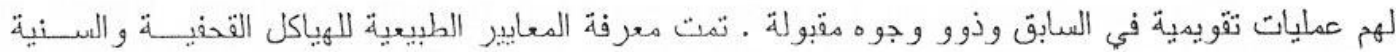

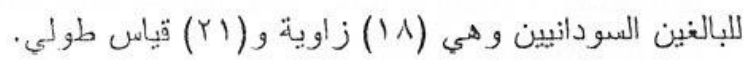

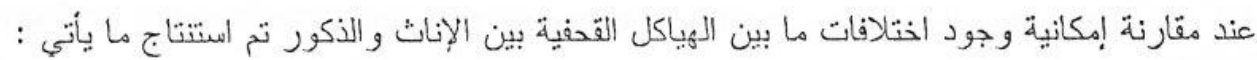

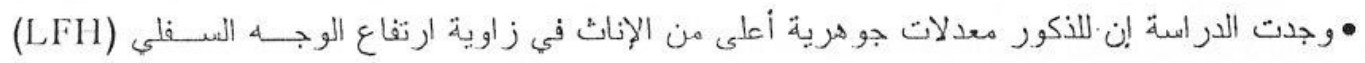

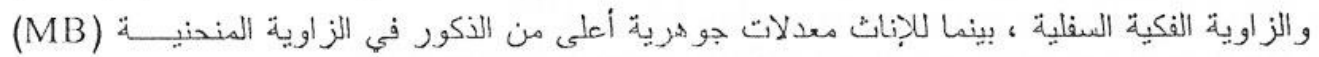

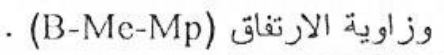

*Fadhil Yassin JASIM; BDS. CES, DSO: Assistant Prof. Department of Pedodontics, Orthodontics and Preventive Dentistry, College of Dentistry, University of Mosul, Mosul, IRAQ.

** Adam Ibrahim ADAM; BDS, MSc: Republic of Sudan. 


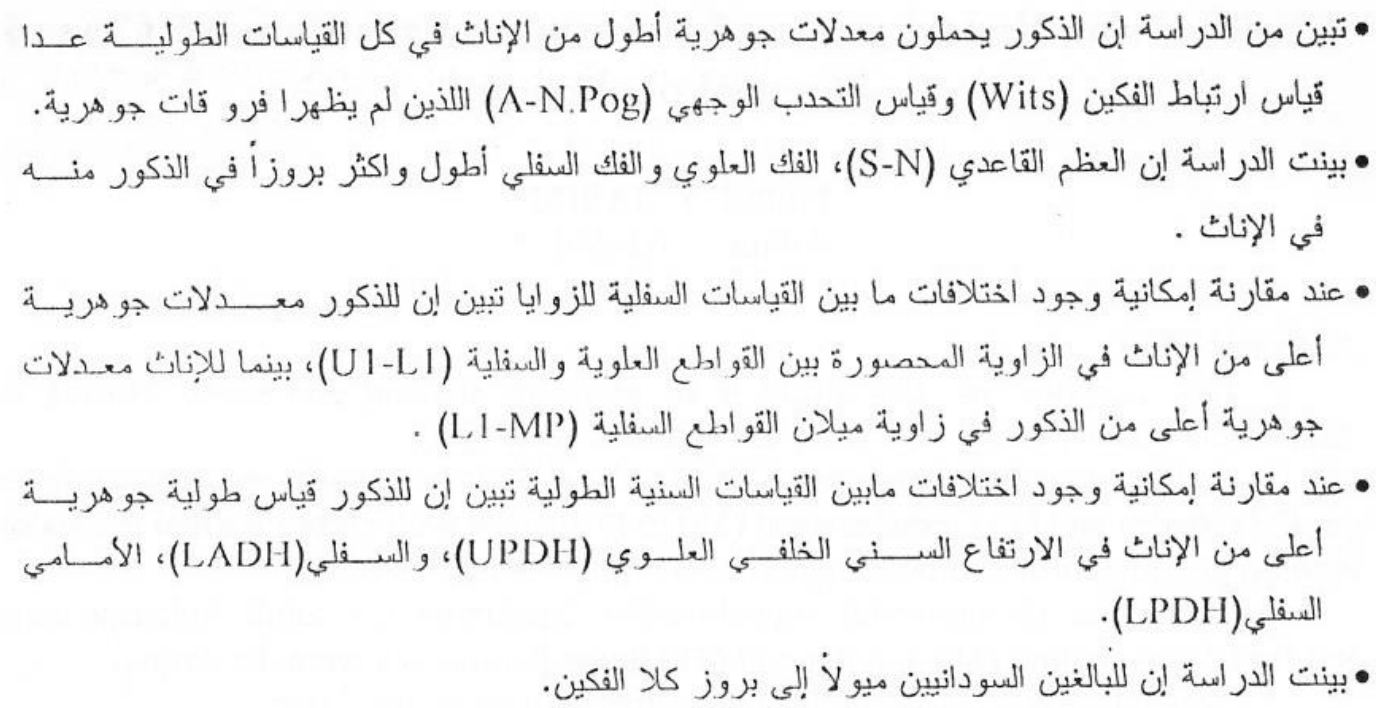

\section{INTRODUCTION}

Cephalometric studies of different ethnic groups are now available including Down's (1) study on Caucasian, Cotton ${ }^{(2)}$ whose the first attempt to apply the cephalmetric analysis to ethnic groups other than those of European ancestry and he applied Down's analysis to African-American, Suh's ${ }^{(3)}$ study of Korean, Mitani's ${ }^{(4)}$ study of Japanese, Fahmy ${ }^{(5)}$ for Egyptians, Shalloub et al ${ }^{(6)}$ for Saudi Arabians, Odch (7) for Iraqi, Al-Sahar ${ }^{(8)}$ for Iraqi, EL-Faituri ${ }^{(9)}$ for Libyan, AL-Katifi ${ }^{(10)}$ for Iracii and $\Lambda \mathrm{L}$-Sayagh ${ }^{(11)}$ for Iracji, most of these investigations stated that normal measurements of one group should not be considered normal for other racial groups, different racial groups must be treated according to their own individual characteristics.

Cephalometric norms have been used to determine the location and the severity of any existing denteriecial discrepancies and to evalunte the changes that accompany the growth of the individual and orthodontic treatment, Bishara ${ }^{(12)}$.

The aim of this study is to determine normative information about skeletodental characteristics of the Sudanese population.

\section{MATERIALS AND METHODS}

The sample selected from Sudanese adult students in Mosul, Basrah and Baghdad Universities, (50) males and females of age ranging from 18-25 years with the following criteria:

1. All subjects are Sudanese in origin, whose parents and grandparents are born in Sudan.

2. Good Medical history (Athanasion) ${ }^{(1.3)}$

3. Class I molar and canine relationship (Angle $)^{(14)}$

4. No detectable rotation of teeth (Bishara and Jacobason) ${ }^{(15)}$.

5. No crowding of dental arches (2-4 mm over bite and over jet)

6. No missing or extracted teeth (excluding third molars) (Swierenga et al.) ${ }^{(16)}$.

7. No history of orthodontic treatment, (Bishara et cal.) $\left.{ }^{(12}\right)$. 
Each subject was seated on an ordinary dental chair and asked about his age, name, origin, facial trauma, medical history, orthodontic and prosthetic treatment. All the subjects were clinically examined in Mosul and Baghdad colleges of dentistry.

\section{Cephalometric Landmarks}

The following landmarks were used in this study (figure 1) as described by Coben ${ }^{(17)}$, Ricketts ${ }^{(18,19)}$, Chaconas ${ }^{(20)}$, Rakosi ${ }^{(21)}$, Jacobson and Caufield ${ }^{(22)}$

1. Point S (Sella): The center of the shadow of the sella turcica.

2. Point $N$ (nasion): The most anterior point of nasofrontal suture in the mid sagittal plane.

3. Point Or (orbitale): The lowest point on the inferior margin of the orbit.

4. Point ANS (anterior nasal spine): The anterior tip of the sharp bony process of the maxilla at the lower margin of the anterior nasal opening.

5. Point PNS (posterior nasal spinc): The posterior spine of the palatine bone constituting the hard palate coincides with the lowest point of the pterygomaxillary fissure (PTM).

6. Point $\Lambda$ (subspinal): The most posterior midline point overlying the upper central incisor root apex in the concavity between the anterior nasal spine and the prosthion which is the most inferior point on the alveolar bone overlying the maxillary
incisors.

7. Point B (supramental): The most posterior midline point in the concavity of the mandible between the most superior point on the alveolar bone overlying the lower incisors (infradental) and pogonion.

8. Point Pog (Pogonion): The most anterior point of the bony chin in the median plane.

9. Point PM (protuberance menti): The point at which the shape of the symphysis changes from convex to concave at the upper termination of the heavy cortical bone of the symphysis.

10. Point Me (Menton): The lowest point in the symphyseal shadow of the mandible is seen on the lateral cephalogram

11. Point Gn (ganthian): The most anterior and inferior point of the bony chin is located where the bisector of the angle formed between the facial plane and mandibular plane intersects the outline of the symphysis.

12. Point Go (gonion): The most inferior and posterior point at the angle of the mandible where the bisector of the angle formed by the junction of the tangents to the posterior border of the ramus and inferior border of the mandible meets the mandibular outline.

13. Point Ar (articulare): The point at junction of the posterior border of the ramus and the inferior border of the posterior cranial base.

14. Point Ba (basion): The lowest point on the anterior rim of the foramen magnum in the mid sagittal plane, or the junction of the superior and inferior surfaces of the petrous portion of the occipital bone.

15. Point Po (porion): The highest point of the bony external auditory meatus (anatomic porion).

16. Point Pt (Pterygoid): The anatomical point representing the radiolucent foramen rotundum, located at the junction of foramen rotundum with the upper left region of the pteygomaxillary fissure.

17. Point DC (Condyle): The point in the center of the condylar neck where the Basion-Nasion plane crosses it. 
18. Point SL (symphysis lingual): The lingual point for determining the symphysis depth is the most prominent point on the lingual (posterior) aspect of the symphysis.

19. Point $\mathrm{Xi}$ (at the center of the ramus): The location of this point is keyed geometrically to the FH (Frankfort horizontal) and Pt V (ptergoidroot vertical planes)

The Procedure for constructing the Xi point is as follows:

1. Locate the FH and draw Pt V plane by drawing a line through the distal radiographic outline of the pterygo maxillary fissure and perpendicular to $\mathrm{FH}$.

2. Construct four planes tangents to points $R-1, R-2, R-3$ and $R-4$ on the border of the ramus.

R-1: Deepest point on the anterior border of the ramus and locate halfway between the superior and the inferior curves.

R-2: Located on the posterior border of the ramus, opposite

R-3: Deepest point of the sigmoid notch and halfway between the anterior and the posterior curves.

R-4: Opposite R-3 on the inferior border of the mandible.

3. The constructed planes form a rectangle enclosing the ramus.

4. Xi point is located in the center of the rectangle at the intersection of the diagonals.

20. UIE point (upper incisor edge): The tip of the incisor edge of the most anteriorly placed upper central incisor.

21. LIE point (lower incisor edge): The tip of the incisor edge of the most anteriorly placed lower central incisor.

22. UMT point (upper molar tip): The tip of the mesiobuccal cusp of the maxillary first molar.

23. LMT point (lower molar tip): The tip of the mesiobuccal cusp of the mandibular first molar

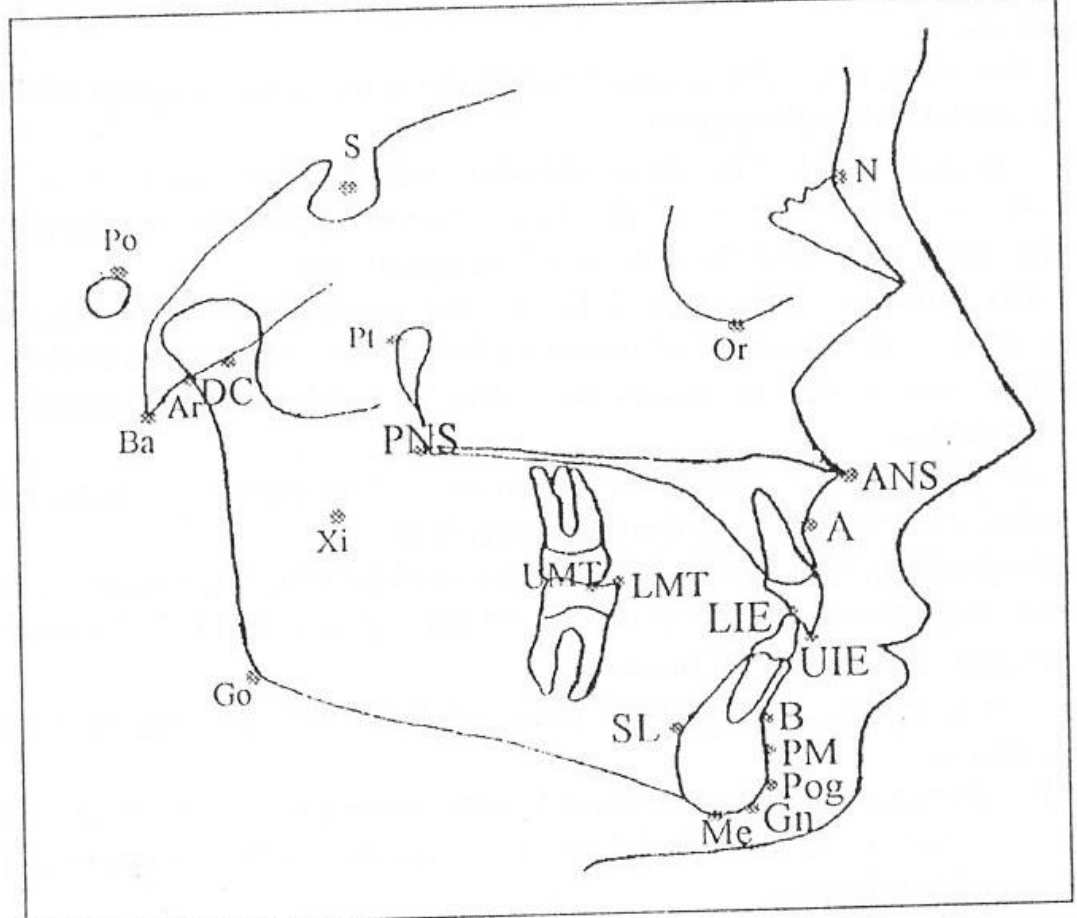

Figure (1): Cephalometric landmarks 


\section{Cephalometric Planes (figure 2)}

1. Basion-Nasion planc (Ba-N): $\Lambda$ line extends from Basion to Nasion (Ricketts)
$($ (Mc Namara)

2. Frankfort horizontal plane (FII): plane extends from the anatomical porion and orbitale (Ricketts) ${ }^{(18)}$, (Swierengea $e t$
al. $)^{(16)}$.

3. Occlusal plane (OP): A line Joining the mid point of the over lap of the mesiobuccal cusps of the upper and lower first molars with the point bisecting the overbite of the incisors. (Stiener) ${ }^{(24)}$, (Jacobson) ${ }^{(22)}$.

4. palatal plane (PP) extends from anterior nasal spine to posterior nasal spine. (Ricketts) $^{(19)}$, (Rakosi) ${ }^{(21)},\left(\right.$ Swierenga et al.) ${ }^{(16)}$

5. Mandibular plane (MP): Extends from gonion to menton forming a line tangent to the lower border of the mandible (Foster) ${ }^{(25)}$.

6. Facial plane (FP): extends fiom nasion to pogonion (Down's) ${ }^{(1)}$, (Mc Namara) ${ }^{(23)}$.

7. Facial axis (Pt. Gn.): $\Lambda$ line, which forms the central axis of the face, drawn between pterygoid point and gnathion (Ricketts) ${ }^{(18)}$; (Swierenga) ${ }^{(16)}$.

8. A- Pog. Line (dental line) (line of compensation): A line extends from point A to Pogonion and represents the maxillo mandibular relation ship (Ricketts) ${ }^{(18)}$; (Solow)
; (Chaconas) ${ }^{(20)}$.

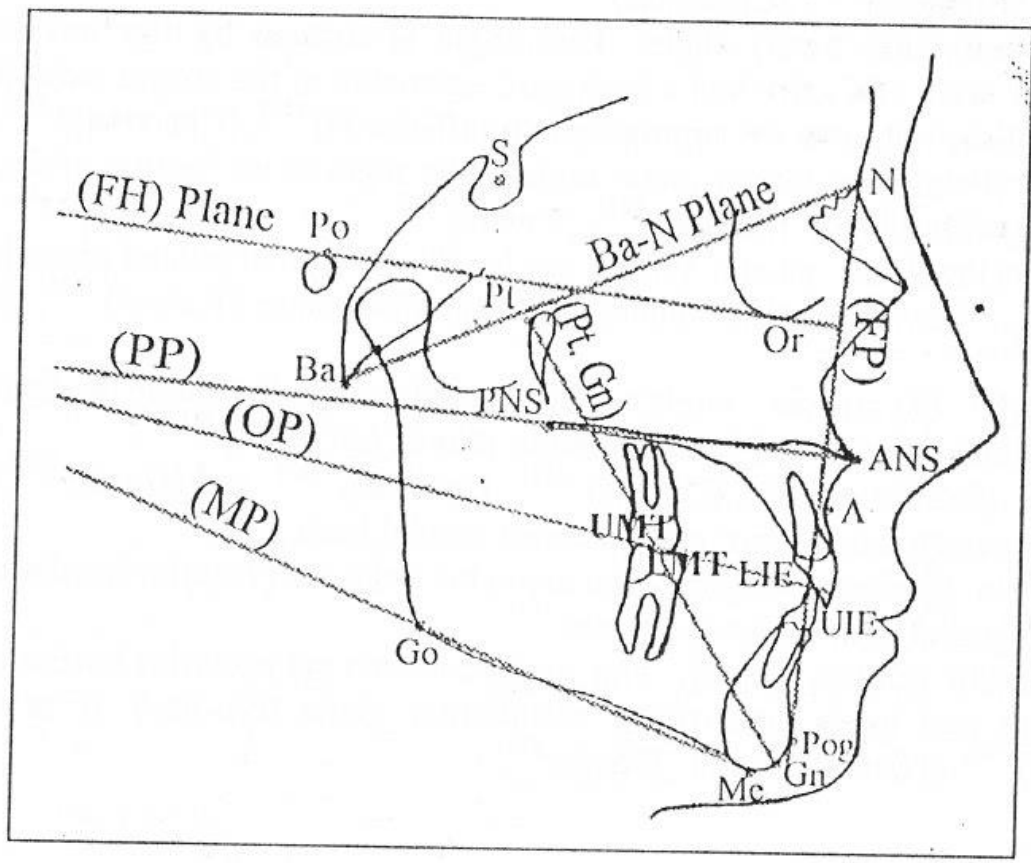

Figure (2): Cephalometric planes

\section{Cephalometric Measurement Techniques}

\section{Skeletal Angular Measurements (figure 3)}

1. S.N.A: Inward angle toward the cranium formed by the intersection of SN and NA. It indicates the anteroposterior position of the maxilla in relation to the anterior cranial base. 
2. S.N.B. Inward angle toward the cranium formed by the intersection of $\mathrm{SN}$ and $\mathrm{NB}$. It indicates the anteroposterior position of the mandible.

3. A.N.B: Angle between NA and NB lines represents the difference between SNA and SNB angles. It describes the relative anteroposterior position of the maxilla to the mandible.

The angles SNA, SNB, ANB were described by (Tweed) ${ }^{(27)}$, (Downs) ${ }^{(1)}$, (Riedel) ${ }^{(28)}$, (Jacobson) ${ }^{(22)}$, (Connor and Moshiri) ${ }^{(29)}$, (Swierenga et al.) $\left(^{16)}\right.$.

4. FP-FII (facial angle): The angle between Frankfort horizontal plane and facial plane represents the degree of mandibular prognathism to carniofacial complex. The most posterio inferior angle is measured.

5. F-Ba-N (facial axis): The angle between the facial axis and the basion-nasion line is measured as the most posterio inferior angle.

6. FMA (Frankfort mandibular plane angle): The angle of inclination of the mandible to the carniofacial complex is formed at the point of intersection of the Frankfort horizontal plane and the mandibular plane. The angle (FP-FII, F-Ba.N, and FMA) were described by (Ricketts) ${ }^{(18,19)}$, and (Swieranga et al.) ${ }^{(16)}$.

7. LFII (lower facial height) angle: This angle is formed by the intersection of a line from the anterior spine to the center of the ramus and the corpus axis, from the ramus center to the $\mathrm{Pm}$ point. It describes the divergence of the oral cavity with growth (Ricketts) ${ }^{(19)}$; (Chaconas) ${ }^{(20)}$

8. MB (Mandibular bend) angle: This angle is formed by the intersection of the condylar axis (DC-Xi) and a backward extension of the corpus axis (Xi-P'm) from center of the ramus to the supra pogonion (Ricketts) ${ }^{(19)}$; (Chaconas) ${ }^{(2))}$

9. PP-MP (Palatomandibular plane angle): The angle of inclination of the mandibular to the maxillary basc. (Rakosi) ${ }^{(21)}$; (Nanda) ${ }^{(30)}$

10.PP-FII (liankfort palatal plane) angle: The angle of palatal plane inclination is measured between palatal plane and lianklort plane. (Rakosi) ${ }^{(21)}$; (Swierenga et al. $)^{(16)}$

11.B.Me-MP (Symphsis angle): The posterior-superior angle is formed by line menton and point $B$ and the mandibular plane (Aki et al.) ${ }^{(31)}$

12.N.S.Ar (Saddle angle): (Downs) ${ }^{(32)}$, (Jarabak) ${ }^{(33)}$ and (Bjork) ${ }^{(34)}$ illustrate the angle between the anterior and posterior cranial base,

13.S.Ar. Go (Articular angle): The angle between the posterior border of ramus and posteriolateral craninal base (Bjork) ${ }^{(35)}$

14. Ar.Go.Me (Gonial angle): The angle between the posterior border of the ramus (Ar-Go) and lower one of the mandibular plane (Go-Me). It as described by (Bjork) ${ }^{(35)}$, (Nanda) ${ }^{(30)}$ and (Viazis) ${ }^{(36)}$

\section{Skeletal Linear Measurements (figure 4)}

They were grouped into horizontal and vertical measurements. The linear horizontal dimensions, which were measured directly between two points as described by, (Wylie) ${ }^{(37)}$. They include:

$\rightarrow \mathrm{S}-\mathrm{N}$ : Represents the anteroposterior extent of the anterior cranial base.

- ANS-PNS: Represents the maxillary length.

$\downarrow$ Go-Me : Represents the mandibular length.

- Symphysis depth (Sym. De): It is defined as the distance from the most anterior point to the most posterior point of the symphsis $(\mathrm{Aki} \mathrm{ef} \mathrm{al.})^{(31)}$

The linear horizontal dimensions, which were measured parallel to Frankfort horizontal (resembling the method of Coben) ${ }^{(17)}$, include: 
- Ar-N: The horizontal distance extends from articular point to the nasion point.

- $\mathrm{r}-\Lambda$ : The distance extends from articular to point $\Lambda$.

- $\Lambda$-Pog: The distance extends from articular to pogonion.

- Wits appraisal: The linear distance measured along the occlusal plane between the two points and intersections of the perpendicular from $A$ and $B$ points to the occlusal plane. (Jacobson) (39), (Abdel-Kader) (40) and (Oktay) (41).

$\rightarrow$ A-N.Pog (facial convexity): This is a linear measurement between point $\mathrm{A}$ and the facial plane. (Wylie) (42); (Bjork) (43) and (Coben) (17).

- N-Me (anterior facial height): The vertical distance from nasion to menton.

- N-ANS (upper anterior facial height): The vertical distance from nasion to anterior nasal spine.

- ANS-Me (lower anterior facial height): The vertical distance between anterior nasal spin and menton represent the anterior height of the masticatory facial component.

- S-Go (posteior facial height): This is the vertical distance between the center of the sella turica and gonion.

- S-Ar: (upper posterior facial height): It is a vertical distance from the center of the sella turcica to the articular.

- Ar-Go (lower posteriorfacial height): It is a vertical distance, which extends from articulare to the gonion representing the ramal height.

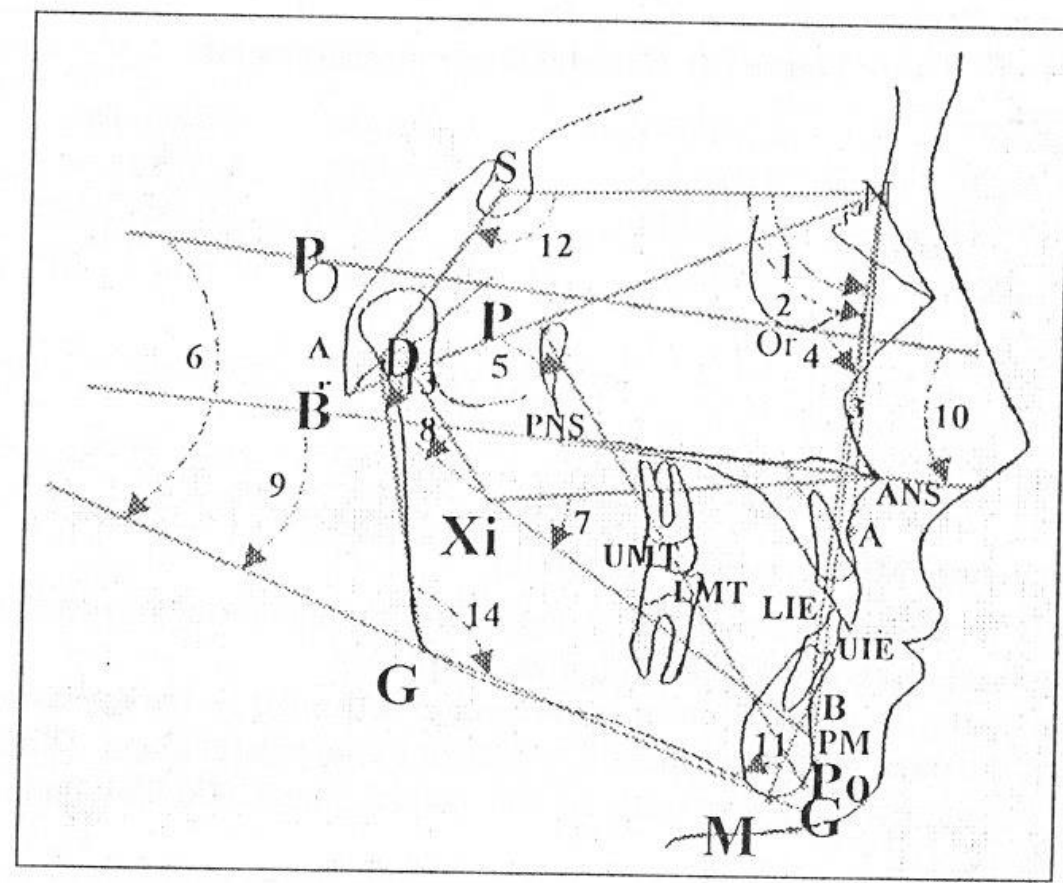

Figure (3): Skeletal angular measurements
1. S. N.A
2. S.N.B
3. A.N.B
4. FP-FH
5. F-Ba. N
6. FMA
7. $\mathrm{LFH}$
8. $\mathrm{MB}$
9. PP-MP
10. PP-FH
11. B. Me-MP
12. N.S.Ar
13. S. Ar. Go
14. Ar. Go. Me 


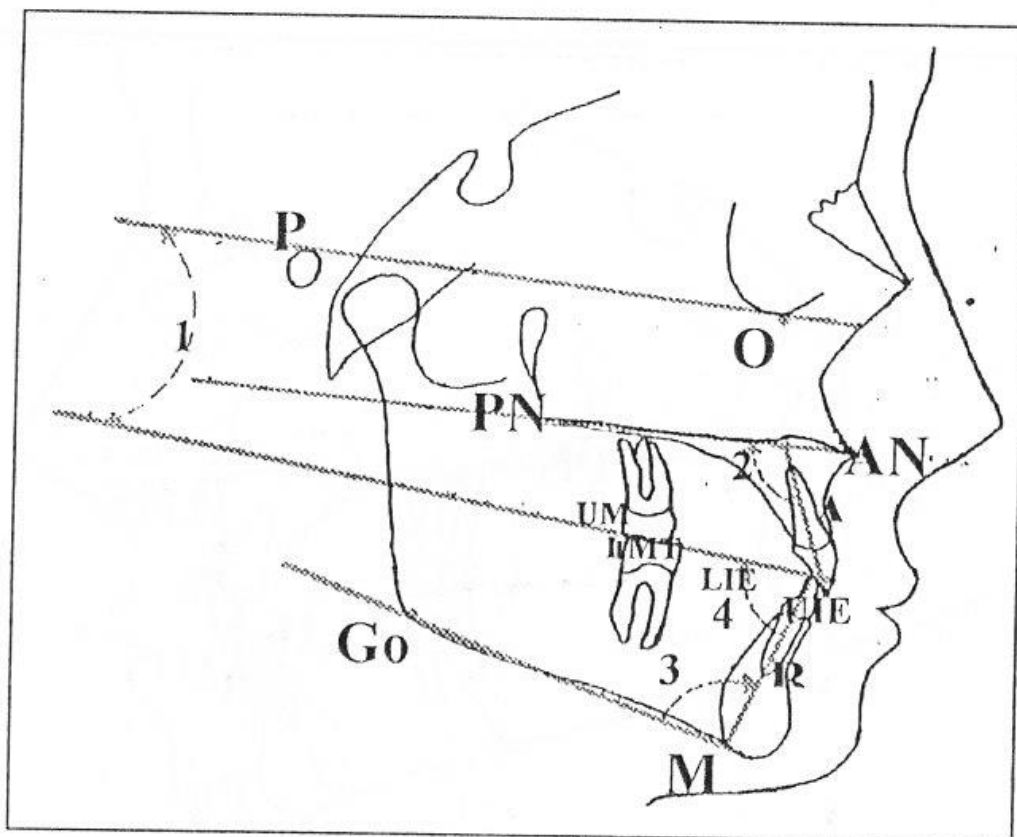

Figure (5): Dental angular measurements
1. OP-FH
2. U1-PP
3. L1-MP
4. U1-L1

\section{Dental Linear Measurements (figure 6)}

- UI-A.Pog (maxillary incisor protrusion): The horizontal distance between the upper incisal edge and the A-Pog. Line. (Downs) ${ }^{(1)}$, (Ricketts) ${ }^{(18,19)}$.

- LI-A.Pog (mandibular incisor protrusion): The horizontal distance between the lower incisal edge and the $\Lambda$-Pog. Line. (Ricketts) ${ }^{(18.19)}$, (McNamara) ${ }^{(23)}$.

- UADH (upper anterior dental height): The perpendicular distance from maxillary central incisor edge (UIE) projected at right angles to the palatal [lane. (Biggerstaff et al. $)^{(43)}$, (Jonson et al. ${ }^{(44)}$.

- LADII (lower anterior dental height): The perpendicular distance from mandibular central incisor edge (LIE) projected at right angles to the mandibular plane (Mp). (Biggerstaff et al.) ${ }^{(43)}$, (Janson et al. $)^{(44)}$.

- UPDII (upper posterior dental height): The perpendicular distance from the

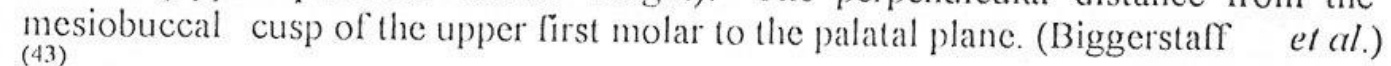

- LPDII (Lower posterior dental height): The perpendicular distance from the mesiobuccal cups of the lower first molar to the mandibular plane. (Biggerstaff $e t$ al.) ${ }^{(43)}$. 


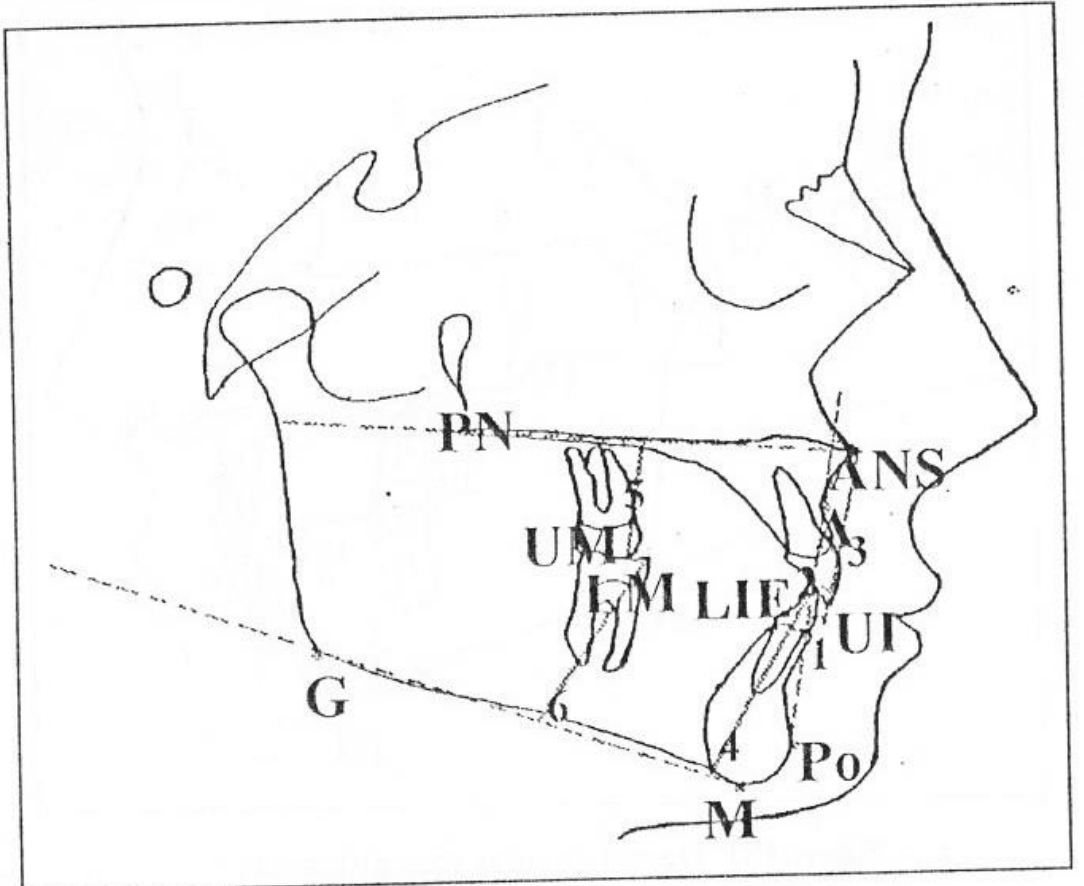

Figure (6): Dental linear measurements
1. U1-A.Pog
2. L1-A.Pog
3. UADH
4. $\mathrm{LAGII}$
5. UPDII
6. L.PDH

Pilot Study

The size of the errors from the tracing of the cephatometric radio graphs, was determined by retracing of (10) randomly selected radiographs, by the same investigator (intra-investigator) (4) weeks after the first tracing to avoid memory bias using paired (student t-test).

Inter-investigator procedure carricd out by repeating the tracing procedures and measurement of the same (10) radiographs by a second investigator with adequate experience

\section{Analysis of the Data}

The statistical analysis included:

1.Descriptive statistics: means, standard deviations of all variables measured for the total sample, male and female groups.

2.Significant differences between male and female samples in the study using (student t-test)

\section{RESULTS}

The mean, standard deviation, minimum and maximum values for males, females and complete sample (total) were recorded and tabulated on tables (1), (2) and (3). 
Table (1): Skeletodental standards (norms) for male of Sudanese adult population

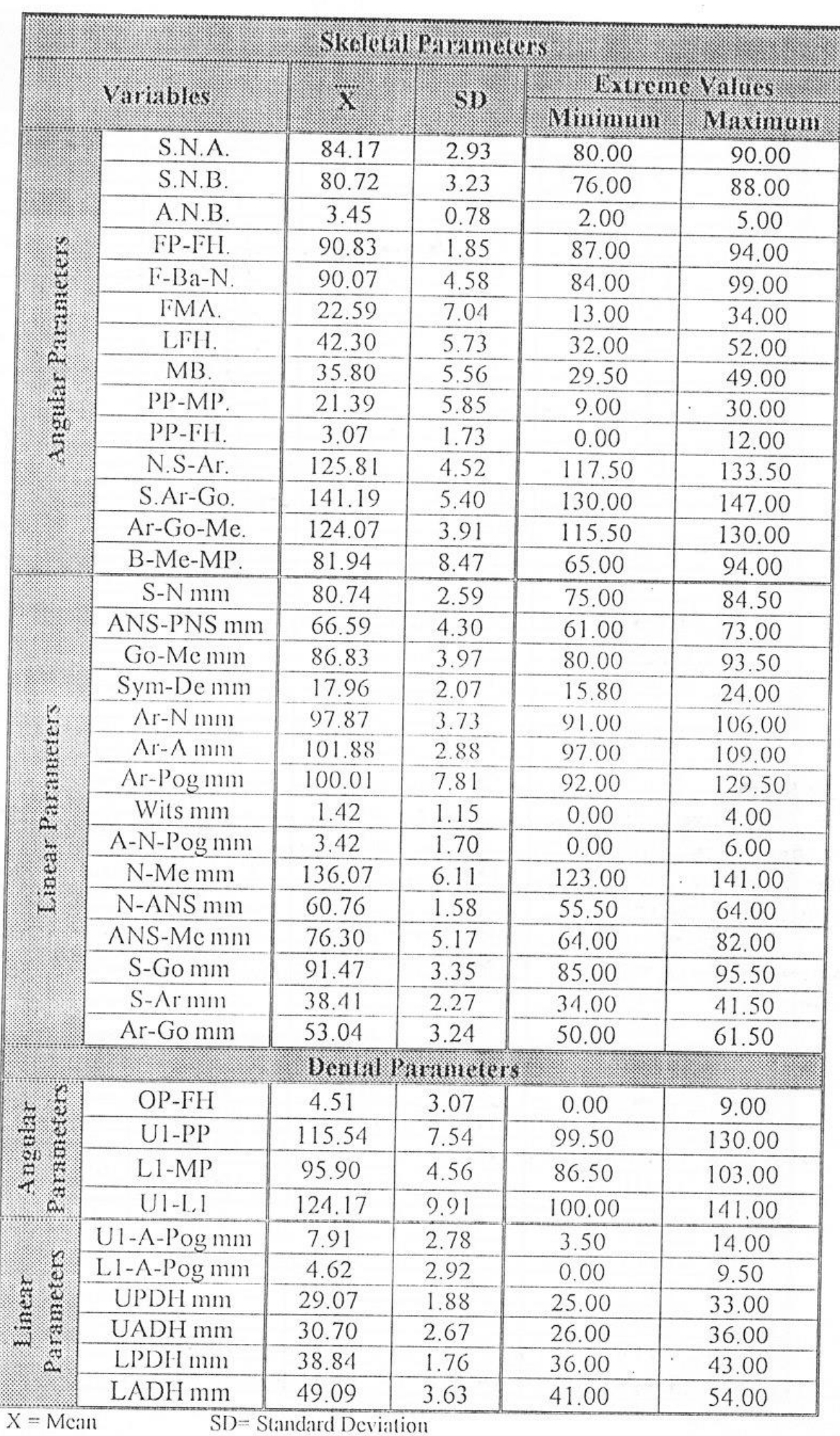


Table (2): Skeletodental standards (norms) for females of Sudanese adult population

\begin{tabular}{|c|c|c|c|c|c|}
\hline \multicolumn{6}{|c|}{ Slacletul Primineters } \\
\hline \multirow{13}{*}{ 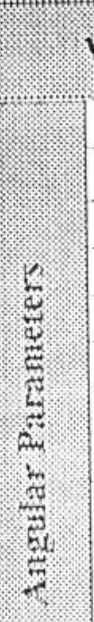 } & \multirow{2}{*}{ Vinitibles } & \multirow{2}{*}{ ( } & \multirow{2}{*}{ s1) } & \multicolumn{2}{|c|}{ 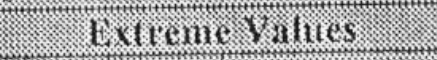 } \\
\hline & & & & Minininim & Mnхинum \\
\hline & S.N.A & 83.28 & 3.69 & 80.00 & 97.00 \\
\hline & S.N.B & 79.41 & 2.69 & 77.00 & 90.00 \\
\hline & A.N.B & 3.87 & 1.38 & 1.50 & 7.00 \\
\hline & FP-FH & 90.70 & 1.08 & 89.00 & 93.00 \\
\hline & $\mathrm{F}-\mathrm{Ba}-\mathrm{N}$ & 88.37 & 1.98 & 86.00 & 93.00 \\
\hline & FMA & 20.71 & 4.15 & 16.00 & 27.00 \\
\hline & LFH & 37.93 & 2.88 & 34.50 & 45.00 \\
\hline & $\mathrm{MB}$ & 39.20 & 3.37 & 33.50 & 45.50 \\
\hline & PP-MP & 22.17 & 1.59 & 17.00 & 24.00 \\
\hline & PP-FH & 1.39 & 1.54 & 0.00 & 5.00 \\
\hline & N.S-Ar & 126.38 & 3.29 & 123.50 & 140.00 \\
\hline \multirow{18}{*}{ 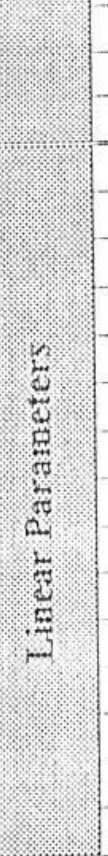 } & S.Ar-Go & 139.66 & 2.18 & 136.00 & 144.00 \\
\hline & $\mathrm{Ar}-\mathrm{Go}-\mathrm{Me}$ & 122.19 & 1.21 & 120.00 & 125.00 \\
\hline & $\mathrm{B}-\mathrm{Me}-\mathrm{MP}$ & 86.38 & 4.16 & 80.00 & 91.50 \\
\hline & $\mathrm{S}-\mathrm{N} \mathrm{mm}$ & 74.10 & 0.64 & 73.00 & 75.00 \\
\hline & ANS-PNS mm & 57.35 & 2.15 & 55.00 & 62.00 \\
\hline & Go-Me mm & 80.17 & 3.33 & 75.00 & 85.00 \\
\hline & Sym-De mm & 14.78 & 1.27 & 13.00 & 17.00 \\
\hline & $\mathrm{Ar}-\mathrm{N} \mathrm{mm}$ & 88.99 & 2.19 & 85.50 & 92.50 \\
\hline & $A r-\Lambda m m$ & 94.68 & 3.22 & 90.00 & 103.50 \\
\hline & $\mathrm{Ar}-\mathrm{P} \operatorname{og} \mathrm{mm}$ & 91.74 & 2.65 & 88.50 & 99.00 \\
\hline & Wits mm & 1.24 & 1.03 & 0.00 & 3.00 \\
\hline & $\Lambda-N-P o g m m$ & 3.09 & 1.87 & 2.50 & 9.00 \\
\hline & N-Me mm & 122.17 & 3.14 & 117.00 & 127.00 \\
\hline & $N-\Lambda N S m m$ & 56.11 & 1.45 & 52.50 & 60.50 \\
\hline & ANS-Me $m m$ & 66.85 & 2.31 & 62.00 & 73.00 \\
\hline & S-Go mm & 80.33 & 1.62 & 75.00 & 83.50 \\
\hline & $\mathrm{S}-\mathrm{Ar} \mathrm{mm}$ & 31.39 & 4.55 & 26.00 & 38.00 \\
\hline & $\mathrm{Ar}-\mathrm{Go} \mathrm{mm}$ & 48.61 & 2.91 & 44.00 & 59.00 \\
\hline \multicolumn{6}{|c|}{ Drutal Prurneter. } \\
\hline \multirow{4}{*}{ 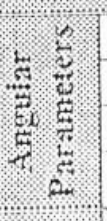 } & $\mathrm{OP}-\mathrm{FH}$ & 4.89 & 1.67 & 2.50 & 7.00 \\
\hline & U1-PP & 117.87 & 5.34 & 111.50 & 129.50 \\
\hline & L1-MP & 102.06 & 4.55 & 95.00 & 110.50 \\
\hline & U1-L1 & 118.43 & 6.97 & 100.00 & 123.50 \\
\hline \multirow{6}{*}{ 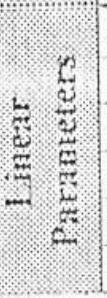 } & U1-A-Pog mm & 7.91 & 1.25 & 6.00 & 9.50 \\
\hline & L.1-A-P'Og mm & 4.10 & 1.19 & 2.50 & 7.00 \\
\hline & UPDH mm & 26.51 & 1.21 & 25.00 & 30.00 \\
\hline & UADH mm & 30.78 & 1.28 & 29.00 & 33.00 \\
\hline & LPDH mm & 34.33 & 2.70 & 30.50 & 40.50 \\
\hline & LADH $\mathrm{mm}$ & 41.81 & 1.02 & 40.00 & 44.00 \\
\hline
\end{tabular}


Table (3): Skeletodental standards (norms) for total Sudanese adult population

\begin{tabular}{|c|c|c|c|c|c|}
\hline \multicolumn{6}{|c|}{ Sketefal Parancters } \\
\hline & Variables & \multirow{2}{*}{ X } & \multirow{2}{*}{810} & \multicolumn{2}{|c|}{ Exritent Vilires } \\
\hline & (1) & & & Mininunu & Maxilüuи \\
\hline & S.N.A & 83.76 & 3.30 & 80.00 & 97.00 \\
\hline & S.N.B & 80.12 & 3.04 & 76.00 & 90.00 \\
\hline \multirow{12}{*}{ 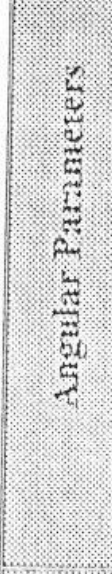 } & A.N.B & 3.64 & 1.11 & 1.50 & 7.00 \\
\hline & FP-FH & 90.77 & 1.53 & 87.00 & 94.00 \\
\hline & $\mathrm{F}-\mathrm{Ba}-\mathrm{N}$ & 89.29 & 3.69 & 84.00 & 99.00 \\
\hline & FMA & 21.72 & 5.91 & 13.00 & 34.00 \\
\hline & LFH & 40.29 & 5.10 & 32.00 & 52.00 \\
\hline & $\mathrm{MB}$ & 37.36 & 4.94 & 29.50 & 49.00 \\
\hline & PP-MP & 21.75 & 4.41 & 9.00 & 30.00 \\
\hline & PP'-III & 3.92 & 8.92 & 0.00 & 12.00 \\
\hline & N.S- $\Lambda r$ & 126.08 & 3.97 & 117.50 & 140.00 \\
\hline & $\mathrm{S} A \mathrm{r}-\mathrm{Go}$ & 140.48 & 4.27 & 130.00 & 147.00 \\
\hline & $\mathrm{Ar}-\mathrm{Go}-\mathrm{Me}$ & 123.21 & 3.11 & 115.50 & 130.00 \\
\hline & B-Me-MP & 83.99 & 7.13 & 65.00 & 94.50 \\
\hline \multirow{15}{*}{ 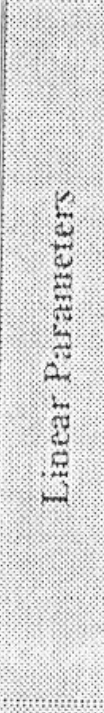 } & $\mathrm{S}-\mathrm{N} \mathrm{mm}$ & 77.69 & 3.86 & 73.00 & 84.50 \\
\hline & ANS-PNS mm & 62.34 & 5.79 & 55.00 & 73.00 \\
\hline & Go-Me mm & 83.77 & 4.96 & 75.00 & 93.50 \\
\hline & Sym-De mm & 16.50 & 2.36 & 13.00 & 24.00 \\
\hline & $\Lambda \mathrm{r}-\mathrm{N} \mathrm{mm}$ & 93.79 & 5.43 & 85.50 & 106.00 \\
\hline & $\Lambda \mathrm{r}-\Lambda \mathrm{mm}$ & 98.57 & 4.71 & 90.00 & 109.00 \\
\hline & Ar-Pog mm & 96.21 & 7.27 & 88.50 & 129.50 \\
\hline & Wits mm & 1.34 & 1.09 & 0.00 & 4.00 \\
\hline & A-N-Pog $m m$ & 4.19 & 1.95 & 0.00 & 9.00 \\
\hline & N-Me mm & 129.68 & 8.55 & 117.00 & 141.00 \\
\hline & $\mathrm{N}-\mathrm{ANS} \mathrm{mm}$ & 58.62 & 2.78 & 52.50 & 64.00 \\
\hline & ANS-Me mm & 71.95 & 6.26 & 62.00 & 82.00 \\
\hline & S-Go mm & 86.35 & 6.21 & 75.00 & 95.50 \\
\hline & $S-\Lambda \mathrm{r} m \mathrm{~m}$ & 35.18 & 4.95 & 26.00 & 41.50 \\
\hline & $\mathrm{Ar}-\mathrm{Go} \mathrm{mm}$ & 51.00 & 3.79 & 44.00 & 61.50 \\
\hline \multicolumn{6}{|c|}{ Detulul Patrumeterts } \\
\hline \multirow{4}{*}{ 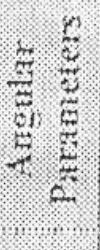 } & $O P-1 \% H$ & 4.68 & 2.51 & 0.00 & 9.00 \\
\hline & U1-PP & 116.61 & 6.66 & 99.50 & 130.00 \\
\hline & L1-MP & 98.73 & 5.47 & 86.00 & 110.50 \\
\hline & U1-L1 & 121.53 & 9.07 & 100.00 & 141.00 \\
\hline \multirow{6}{*}{ 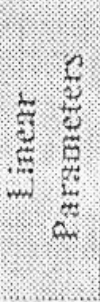 } & U1-A-Pog mm & 7.91 & 2.16 & 3.50 & 14.00 \\
\hline & L1-A-Pog $\mathrm{mm}$ & 4.38 & 2.28 & 0.00 & 9.50 \\
\hline & UPDH mm & 27.90 & 2.05 & 25.00 & 33.00 \\
\hline & UADII $\mathrm{mm}$ & 30.78 & 2.13 & 26.00 & 36.00 \\
\hline & LPDH mm & 36.67 & 3.17 & 30.50 & 43.00 \\
\hline & LADH mm & 45.76 & 4.56 & 40.00 & 54.50 \\
\hline
\end{tabular}

$\mathrm{X}=$ Mcan $\quad \mathrm{SD}=$ Standard Deviation 
Table (4) represents the skeletodental comparison between males and females and groups as follows:

\section{Skeletal Angular Parameters}

The males were significantly greater than females in the lower facial height (LFH) and the gonial angle (Ar. Go. Me) while the females were significantly greater than the males in (MB and B-Me-Mp) angles.

\section{Skeletal Linear Parameters}

The males were significantly greater than the females in all the skeletal linear parameters except (Wits appraisaland A-N-Pog.) which revealed no difference between males and females.

\section{Dental Angular Parameters}

The males were significantly greater than the females in the interincisal angle $\left(\mathrm{U}_{1}-\mathrm{L}_{1}\right)$ while the females were significantly greater than the males in the lower incisor inclination $\left(\mathrm{L}_{1}-\mathrm{Mp}\right)$ angle.

\section{Dental Linear Parameters}

The males were signilicantly greater than the females in upper posterior dental height (UPDII), lower posterior dental height (LPDII) and lower anterior dental height (LADH).

\section{DISCUSSION}

\section{Comparison between the Males and Females}

\section{Skeletal Angular Parameters}

$\Lambda$ s expressed by S.N.A, S.N.B and facial angle (FP-FII) the findings of this study showed no significant differences related to the anteroposterior dimensions for both sexes. These findings came in agreement with Shalhoub et al. ${ }^{(6)}$, EL-Faituri ${ }^{(9)}$, and AL-Sayagh (11).

Although the males exhibited slight greater mean values of the facial axis angle $(\mathrm{F}-\mathrm{Ba}-\mathrm{N})$ than the female, but the difference was not statistically significant. These findings came in agreement with Ricketts ${ }^{(18)}$ and Swierenga et al. ${ }^{(16)}$

The angle of inclination of the mandible to the craniofocial complex (FMA) and the angle of inclination of the mandible to the maxillary base (PP-MP) revealed no significant difference between both sexes, whereas, the mean value of males was more than that of the females in $(\mathrm{FM} \Lambda)$, while the females showed greater mean values than the males in the (PP-MP). These findings differs from that of $\mathrm{Al}$ Sayagh (11) who found significant difference between both sexes in the (FMA and PPMP') angles. Also the angle of palatal plane inclination exhibited no significant differences between both sexes, but the males showed more mean values than females which were similar to Swierenga ef al. ${ }^{(16)}$ and $\mathrm{AL}$-Sayagh ${ }^{(11)}$ findings.

Although females exhibited slightly high mean value than the males in the (Saddle angle) (N.S.Ar), and the males exhibited slightly high mean values than the females in the (articular angle) (S.Ar. Go), but these differences were not significant. They were similar to Jacobson ${ }^{(45)}$, Rakosi ${ }^{(21)} \wedge$ L-Sahaf ${ }^{(8)}$ and EL-Faituri ${ }^{(9)}$ findings. 
Table (4): Comparison between skeletodental parameters for males and females of Sudanese adult population

\begin{tabular}{|c|c|c|c|c|c|c|c|}
\hline \multicolumn{8}{|c|}{ Skelotal Parnmeters } \\
\hline \multirow{2}{*}{\multicolumn{2}{|c|}{ Yinitiles }} & \multicolumn{2}{|c|}{ Mules } & \multicolumn{2}{|c|}{ irinialos } & \multirow[b]{2}{*}{ firvilue } & \multirow[b]{2}{*}{ Signifilinney } \\
\hline & & X. & $\mathrm{SB}$ & X & SD & & \\
\hline \multirow{14}{*}{ 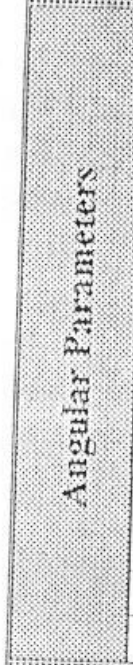 } & S.N.A & 84.17 & 2.93 & 83.28 & 3.69 & 0.89 & N.S. \\
\hline & S.N.B & 80.72 & 3.23 & 79.41 & 2.69 & 2.37 & N.S \\
\hline & A.N.B & 3.45 & 0.78 & 3.87 & 1.38 & 1.91 & N.S \\
\hline & FP-FH & 90.83 & 1.85 & 90.70 & 1.08 & 0.90 & N.S \\
\hline & $\mathrm{F}-\mathrm{Ba}-\mathrm{N}$ & 90.07 & 4.58 & 88.37 & 1.98 & 2.70 & N.S \\
\hline & FMA & 22.59 & 7.04 & 20.71 & 4.15 & 1.26 & N.S \\
\hline & LFH & 42.30 & 5.73 & 37.93 & 2.88 & 10.95 & S. \\
\hline & $\mathrm{MB}$ & 35.80 & 5.56 & 39.20 & 3.37 & 6.54 & S. \\
\hline & PP-MP & 21.39 & 5.85 & 22.17 & 1.59 & 0.39 & N.S. \\
\hline & PP-FH & 3.07 & 1.73 & 1.39 & 1.54 & 3.60 & N.S. \\
\hline & N.S-Ar & 125.81 & 4.52 & 126.38 & 3.29 & 0.25 & N.S. \\
\hline & S.Ar-Go & 141.19 & 5.40 & 139.66 & 2.18 & 1.61 & N.S. \\
\hline & Ar-Go-Me & 124.07 & 3.91 & 122.19 & 1.21 & 4.95 & S. \\
\hline & B-MeMP & 81.94 & 8.47 & 86.38 & 4.16 & 5.23 & $\mathrm{~S}$. \\
\hline \multirow{15}{*}{ 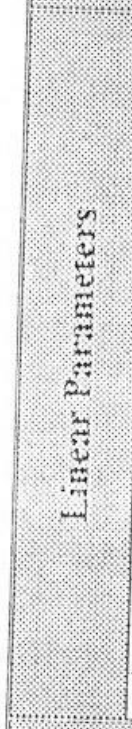 } & $\mathrm{S}-\mathrm{N} \mathrm{mm}$ & 80.74 & 2.59 & 74.10 & 0.64 & 143.47 & S. \\
\hline & ANS-PNS mm & 66.59 & 4.30 & 57.35 & 2.15 & 87.46 & $\mathrm{~S}$ \\
\hline & Go-Me mm & 86.83 & 3.97 & 80.17 & 3.33 & 40.47 & $\mathrm{~S}$. \\
\hline & Sym-De mm & 17.96 & 2.07 & 14.78 & 1.27 & 40.77 & $\mathrm{~S}$. \\
\hline & $\mathrm{Ar}-\mathrm{N} \mathrm{mm}$ & 97.87 & 3.73 & 88.99 & 2.19 & 100.48 & S. \\
\hline & $\Lambda \mathrm{r}-\Lambda \mathrm{mm}$ & 101.88 & 2.88 & 94.68 & 3.22 & 69.67 & S. \\
\hline & $\Lambda r-P o g m m$ & 100.01 & 7.81 & 91.74 & 2.65 & 23.47 & S. \\
\hline & Wits mm & 1.42 & 1.15 & 1.24 & 1.03 & 0.33 & N.S. \\
\hline & $A-N-P \circ g m m$ & 3.42 & 1.70 & 3.09 & 1.87 & 10.86 & N.S. \\
\hline & $\mathrm{N}-\mathrm{Me} \mathrm{mm}$ & 136.07 & 6.11 & 122.17 & 3.14 & 96.85 & $\mathrm{~S}$. \\
\hline & $\mathrm{N}-\Lambda N S \mathrm{~mm}$ & 0.70 & 1.58 & 50.11 & 1.45 & 116.18 & S. \\
\hline & ANS-Me mm & 76.30 & 5.17 & 66.85 & 2.31 & 65.43 & $\mathrm{~S}$. \\
\hline & S-Go mm & 91.47 & 3.35 & 80.33 & 1.62 & 212.22 & $\mathrm{~S}$. \\
\hline & S-Ar mm & 38.41 & 2.27 & 31.39 & 4.55 & 49.91 & S. \\
\hline & $\mathrm{Ar}-\mathrm{Go} \mathrm{mm}$ & 53.04 & 3.24 & 48.61 & 2.91 & 25.48 & S. \\
\hline \multicolumn{8}{|c|}{ Dentinl Parmueters: } \\
\hline \multirow{4}{*}{ 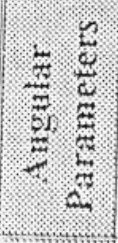 } & $\mathrm{OP}-\mathrm{FH}$ & 4.51 & 3.07 & 4.89 & 1.67 & 0.27 & N.S. \\
\hline & U1-PP & 115.54 & 7.54 & 117.87 & 5.34 & 1.55 & N.S. \\
\hline & L1-MP & 95.90 & 4.56 & 102.06 & 4.55 & 22.65 & S. \\
\hline & U1-L1 & 124.17 & 9.91 & 118.43 & 6.97 & 5.40 & $\mathrm{~S}$. \\
\hline \multirow{6}{*}{ 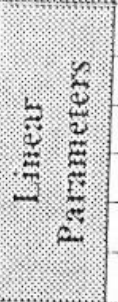 } & U1-A-Pog $m m$ & 7.91 & 2.78 & 7.91 & 1.25 & 0.00 & N.S. \\
\hline & L1-A-Pog mm & 4.62 & 2.92 & 4.10 & 1.19 & 0.65 & N.S. \\
\hline & UPDH mm & 29.07 & 1.88 & 26.51 & 1.21 & 31.55 & $\mathrm{~S}$. \\
\hline & $\mathrm{UADH} \mathrm{mm}$ & 30.70 & 2.67 & 30.87 & 1.28 & 0.07 & N.S. \\
\hline & LPDH $\mathrm{mm}$ & 38.84 & 1.76 & 34.33 & 2.70 & 50.53 & S. \\
\hline & $\mathrm{LADH} \mathrm{mm}$ & 49.09 & 3.63 & 41.81 & 1.02 & 85.55 & $S$. \\
\hline
\end{tabular}




\section{Lower Facial Height Angle (LFH)}

This angle was more significant in males than in females, which is similar to AL-Katifi ${ }^{(10)}$ and not similar to Park ef al. ${ }^{(46)}$ and $\mathrm{AL}$-Sayagh ${ }^{(11)}$. These findings revealed that the male's oral cavity is more divergent than that of the females.

\section{Mandidular Bend Angle (MB)}

This angle was highly significant in females than males which is contradicted with $\Lambda$ L-Sayagh (11) findings who found that the males were highly significant than the females, and similar to that of Jensen and palling ${ }^{(47)}$ who attribute this difference to the stronger and heavier muscle mass in male than females. These findings indicated that the females had a tendency to forward rotation of the mandible.

\section{Gonial Angle (Ar. Go. Me)}

The male were highly significant than females which in agreement with flynn ef al. ${ }^{(48)}$ and EL-Faitari ${ }^{(9)}$ and disagreement with Jafar ${ }^{(49)}$

\section{The Symplyyses Angle (B-Me-MP)}

The females were highly significant different than the males, these findings are similar to Shalhoub ef al. ${ }^{(6)}$ and disagree with $\mathrm{AL}$-Sayagh ${ }^{(1)}$. These findings as with that of the $(\mathrm{MB})$ angle indicated that the females had a tendency toward forward rotation of the mandible.

\section{Slicletal Linear Parameters}

\section{Horizontal larameters}

The males reflected the expected significant large values of the anterior cranial base (S-N), maxillary length (ANS-PNS) and the mandibular length (Go-Me) than that of the females (table 4). These findings were similar to those AL-Sayagh ${ }^{(11)}$ and NL-Hamdany ${ }^{(50)}$.

The males also were significantly longer than females in the symphysis depth (Sym-De). Aki ef al. ${ }^{(32)}$ and $\Lambda \mathrm{L}-$ Sayagh (ii) got the same findings. According to Nanda and Merril ${ }^{(52)}$ these findings may be due to the bone deposition at the pogonion area, which is highly variable, and appear to be sex linked.

The males also significantly longer than females in the facial depth parameters at point $(A, B$ and Pog.) which expressed by $(A r-N, A r-A$ and $\Lambda r-p o g$. $)$ parameters

For the (Wits apprasial and $\Lambda$-N-Pog.) which were represented anteroposterior relation ship between the maxilla and the mandible, the difference between the males and females failed to be significant. These findings indicated that both sexes had bimaxillary protrusion tendency.

\section{The Vertical Parameters}

\section{The Anterior Facial II eight}

The upper anterior facial height (N-ANS), Lower anterior facial height (ANS-

$\mathrm{Mc}$ ) and the total anterior facial height (N-Mc) were signficantly longer in males than the females. These findings were approximately similar to that of park ef al. ${ }^{(46)}$, ELFaituri ${ }^{(9)}$ and AL-Sayagh ${ }^{(i i)}$. 


\section{The Posterior Facial Height}

The posterior facial height was significantly longer in the males than the females in (S-Ar), (Ar-Go) and the (S-Go). These findings indicated that there was greater growth rate in the males than the females

\section{Dental Angular Parameters}

The occlusal plane cant (OP-FP) and the upper incisor inclination (U1-PP) exhibited no significant differences between both sexes. But the females were slightly greater than the males in their mean values (table 4), which indicated more protrusive upper incisors of the females than their male counterparts.

Whereas the lower incisor inclination (L1-MP) was significantly greater in females. The interincisal (U1-L1) angle was significantly greater in the males than the females. These findings came in contrast to $\mathrm{AL}$-Sayagh ${ }^{(11)}$ findings that found no significant difference in all the dental angular parameters between both sexes.

From these findings both sexes appeared to exhibit bimaxillary dentoalveolar protrusion, but the significant acuteness of the interincisal angle (U1-L1) in the females substantiated the existence of more bimaxillary dento alveolar protrusion in the females than males.

\section{Dental Linear Parameters}

No significant difference between both sexes in the lower and upper incisor protrusion (U1-A-Pog.) and (L1-A-Pog.). These findings support the truth that both sexes had a bimaxillary skeletal and dental protrusion

\section{The Anterior Dental II eight}

No significant differences between both sexes in the upper anterior dental height (UADH). Flym et al. ${ }^{(48)}$ and $\Lambda \mathrm{L}$-Sayagh ${ }^{(11)}$ reported similar findings. On the other hand the males showed significant lower anterior dental height (LADH) greater than that of the females, which came in agreement with $\Lambda \mathrm{L}$-Sayagh ${ }^{(11)}$ findings.

\section{The Posterior Dental Height}

The males were significantly greater than females in both lower and upper posterior dental height, (LPDH) and (UPDH) which reflects the sex difference.

\section{CONCLUSIONS}

- Standard (norms) for skeletal and dental relationships for Sudanese adults is established.

- When comparing the skeletal angular parameters it was found that the males were significantly greater than the females in the lower facial height (LFII) and the gonial angle (Ar-Go- Me), while the females were significantly greater than the males in (MB and B-Me-Mp) angles.

- The Sudanese adults exhibited bimaxillary protrusion tendency.

- Males with longer cranial base than females.

- The males were significantly greater than the females in all skeletal linear parameters except (Wits apprasial and $\Lambda$-N-Pog.) which revealed no significant sex
differences.

- Males with longer upper andlower Jaws than females.

- Males with increased facial height (anteriorlyand posteriorly). 
- Dental comparison: Showed that the males were significantly larger than the females in the interincisal angle (U1-L1), while the females were significantly greater than the males in the (L1-Mp) angle. On the other hand, the males were significantly greater than the females in upper posterior (UPDH), lower posterior (LPDH) and lower anterior (LADH) dental heights .

- When comparing the skeletodental parameters of the this study to those of other studies using nearly the same criteria, differences were observed theses differences may be due to ethic variation.

\section{REFERENCES}

1. Downs WB. Variations in facial relationships, Their significance in treatment and prognosis. Am J Ortho. 1948; 34: 812-840.

2. Cotton WN, Takana WS, Wong WW. The Downs's analysis applied to three other ethnic groups. Angle Ortho. 1951; 21: 213-220.

3. Suh CH. Roentgenographic study on the teeth and skull of Korean modern. Med. 1967; 6: 515-527.

4. Mitani S. A reontgenocephalometric study of seventeen - years old Japanese using several analyses. A thesis presented to the School of Dentistry, Loyola University. 1980.

5. Fahmy MA. Development of cephalometric norms for young Egyptian adults and their comparisons with appropriate American samples. M Sc thesis, Alexandria. Egypt. Alexandria University. 1978.

6. Shalhoub SY, Sarhan OA, Shaikh HS. Adults cephalometric norms for Saudi Arabians with a comparison of value for Saudi and North American Caucasians. $\mathrm{Br}$ Dent J. 1987; 14 (4): 273-279.

7. Odeh FD. Assessment of jaw and dental relationship by the use of lateral skull radiographic eephalometry. Iraqi Dent .J. 1983; 12: 147-154.

8. Al-Sahaf NH. Cross-sectional study of cephalometric standards and associated growth changes. MSc thesis, College of Dentistry, Baghdad University. 1991.

9. El-Faituri H. Cephalometric norms for Libyan population. Arab Dent J. 1994; 1: 3546.

10. Al-Katifi BSh. Prosthodontic cephalometric standards and their relation to facial type in Iraqi Adult Sample (radiographic cephalometric study). MSc thesis, College of Dentistry, Baghdad University. 1994

11. Al-Sayagh NM. Dentoskeletal analysis and facial types of Iraqi adults in Mosul City with class one normal occlusion, ( $\Lambda$ lateral radiographic cephalometric study). MSc thesis, College of Dentistry, Mosul University. 1999.

12. Bishara et al. Cephalometric comparisons of dentofacial parameters between Egyptian and North American adolescents. Am. J Ortho. 1990; 97: 413-421.

13. Athansion AE, Droschl II, Bosch C. Data and patterns of transverse dentofacial structures of 6 to 15 years old children: A postero anterior cephalometric study. 1992: 465-471.

14. Angle FH. Classification of malocclusion. Dent Cosmos. 1889; 41: 264-284.

15. Bishara SE, Jokobsen JR. Longitudinal changes in three normal facial types. $\mathrm{Am} J$ Ortho. 1985; 88: 466-502.

16. Swierenga D, Oesterle LJ, Messersmith ML. Cephalometric values for adult Mexican-Americans. Am.J Ortho Dontofac Orthop. 1994; 106(2): 146-155. 
17. Coben SE. The integration of facial skeletal variations. A serial cephalometric roentgenographic analysis of craniofacial form and growth. Am.J Orthod. 1955; 41: 407-434.

18. Ricketts RM. A Foundation for cephalometric communication. Am J Ortho. 1960b;
46.330-357.

19. Ricketts R M. Perspective in the clinical application of cephalometric. Angle Orthod. 1981; 51: 115-150.

20. Chaconas S J. Postgraduate Dental Handbook. Orthodontics. John Wright and Sons Ltd. England. 1982.

21. Rakosi T. An Atlas and Manual of Cephalometric Radiography. $2^{\text {nd }}$ Edn. Wolfe Medical Publication. Great Britain. 1982. 22. Jacobson $A$, Caufield PW. Introduction to Radiographic Cephalometry. Philadelphia
Lea and Febiger. 1985 .

23. McNamara JA. A method of cephalometric evaluation. Am JOrthod. 1984; 86:
449-469.

24. Steiner CC. Cephalometrics for you and me. Am J Orthod. 1953; 39: 729.

25. Foster TD. $\Lambda$ Textbook of Orthodontics. $2^{\text {nd }}$ Edn. Blackwell Scientific Publications. 1985.

26. Solow B. The dentoalveolar compensatory mechanism background and clinical implications. Br.J Orthod. 1980; L7: 145-161.

27. Tweed $\mathrm{CH}$. The Frankfort-Mandibular plane angle in orthodontic diagnosis classification, treatment planning and prognosis. Am J Orthod. 1946; 32: 175-230.

28. Riedel RA. The relation of maxillary structures to cranium in malocclusion and in normal occlusion. Angle Orthod. 1952; 22:142-145.

29. Connor $\Lambda \mathrm{M}$, Moshiri F. Orthognathic surgery norms for $\Lambda$ merican black patients. Am Jorthod. 1985; 87: 119-134.

30. Nanda SK. Growth patterns in subjects with long and short faces. Am.JOrtho Dentofac Orthop. 1990; 98: 247-258.

31. Aki TI, Nanda RS, Currier F, Nanda SK. Assessment of symphysis morphology as a predictor of the direction of mandibular growth. Am J Orthod Dentofac Orthop. 1994; 106-109.

32. Downs WB. Analysis of dentofacial profile. Angle Orthod. 1956; 26: 191-212.

33. Jarabak JR, Fizzell FA. Technique and Treatment with Light Wire Edgewise Appliances. $2^{\text {nd }}$ Edn. CV Mosby Co, St Louis. 1972.

34. Bjork A, Skiller V. Growth in width of maxilla studied by the implant method. Ibid. 1974; 8: 26.

35. Bjork A. The face in profile. Lund: Berlingska Baktryckerict. 1947.

36. Viazis $\Lambda D$. Cephalometric evaluation of skeletal open and deep bite tendencies. $J$ Clin Ortho. 1992: 338-343.

37. Wylie WL. The assessment of anteropoteriior dysplasia. Angle Orthod. 1947; 17: 97-109.

38. Bjork A. Cranial base development. Am J Orthod. 1955; 41: 198-225.

39. Jacobson $\Lambda$. The" Wits" appraisal of jaw disharmony. Am J Orthod. 1975; 67: 125138.

40. Abdel-Kader HM. Quadrilateral analysis of adults: An approach to a basic concept for facial harmony. Egypt J Orthod. 1988; 2(2): 83-100.

41. Oktay H. $\wedge$ comparison of $\Lambda \mathrm{NB}$, Wits, $\Lambda \mathrm{F}-\mathrm{BF}$, and $\Lambda$ PDI measurements. $A m J$ Orthod. 1991; 99: 112-118.

42. Wylie WL, Johnson EL. Rapid evaluation of facial dysplasia in the vertical plane. Angle Orthod. 1952; 22: 165-182. 
43. Biggerstaff RH, Allen RC, Tuncay OC, Berkowitz. J. A vertical cephalometric analysis of the human craniofacial complex. Am.J Orthod. 1977; 72 (4): 397-405.

44. Janson GRP, Metaxas $\Lambda$, Woodside DG. Variation in maxillary and mandibular molar and incisor vertical dimension in 12-year-old subject with excess, normal and short lower anterior face height. Am.J (Orthod Dentofac Orthop. 1994; 106: 409-418.

45. Jacobson A. The craniofacial skeleton of the South African Negro. Am.J Orthod. 1978; 73: 681-691.

46. Park I, Bowman D, Klapper L. A cephalometric study of Korean adults. Am.J Orthod Dentofac Orthop. 1989; 96 (1): 54-59

47. Jensen E, Palling $M$. The gonial angle. Am J Orthod. 1954; 4: 243-249.

48. Flym TR. Ambrogi RI, Zeichner SJ. Cephalometric norms for orthognathic surgery in black American adults. J Oral Maxillofac Surg. 1989; 47: 30-39.

49. Jafar KK. The relation of the gonial angle to some cephalometric planes and angles in Iraci young adults ( $\Lambda$ cross-sectional study). MSc thesis, College of Dentistry, Baghladad University. 1998.

50. Al-Hamdany $\mathrm{AKh}$. Three-dimensional analysis of mandible in Class one normal occlusion of Iraqi adult students (18-25 years) in Mosul City ( $\Lambda$ cephalometric study). MSc thesis, College of Dentistry, Mosul University. 2000

51. Nanda RS, Merrill RM. Cephalometric assessment of sagittal relationship between maxilla and mandible. Am. J Orthod Dentofac Orthop. 1994; 105: 328-344. 